\title{
REFLEXOS DO MACHISMO ESTRUTURAL BRASILEIRO EM TEMPOS DE COVID 19: QUANDO O DISTANCIAMENTO SOCIAL É TÃO LETAL QUANTO O VÍRUS
}

\section{REFLECTIONS OF BRAZILIAN STRUCTURAL CHAUVINISM IN THE TIME OF COVID 19: WHEN SOCIAL DISTANCE IS AS LETHAL AS THE VIRUS}

\author{
Amanda Santos de Oliveira* \\ Gabriela Carvalho Oliveira** \\ Janaína Sabina Cardoso***
}

\begin{abstract}
Resumo: $O$ presente artigo se trata de uma pesquisa bibliográfica, através da metodologia exploratória, que ergueu seu referencial teórico na busca por levantamento de dados em tempos de pandemia, no qual o número de denúncias feitas em relação a violência doméstica aumentou $34 \%$ entre março e abril deste ano em comparação ao mesmo período do ano anterior, conforme dados recentes que serão discutidos nessa produção. Esse aumento exponencial de casos de agressões e feminicídios reafirmam a preponderância de relacionamentos abusivos no Brasil e o quanto a cultura do silêncio das vítimas de violência ainda é latente e estruturalmente construído. Desde a falas como "em briga de marido e mulher ninguém mete a colher até "apanha porque gosta fica porque quer". Nesse cenário pandêmico, em que o distanciamento social é a orientação precípua da OMS, o silêncio dessas mulheres e o consequente afastamento de amigos e parentes próximos torna-se efetivamente os maiores cúmplices da violência de gênero.
\end{abstract}

Palavras-chave: Pandemia. Machismo Estrutural. Violência Doméstica. Direitos Humanos.

Abstract: This article is based on a bibliographical research conducted by means of the exploratory methodology arising from an analysis of domestic violence data in pandemic times, the number of complaints made regarding domestic violence increased 34\% between March and April this year compared to the same period last year, according to recent data that will be discussed in this production. This exponential increase in cases of aggression and feminicides reaffirms the preponderance of abusive relationships in Brazil and the extent to which the culture of silence of victims of violence is still latent and structurally constructed. From the words like "in a fight between husband and wife, no one gets to pick it up until" they get beaten because they like it because they want to ". In this pandemic scenario, in

\footnotetext{
* Graduada em Direito pelo Centro Universitário AGES, UniAGES. Pós-graduada Lato Sensu em Direito de Processo Civil pela Faculdade Futura. E-mail: amanda.oliveira2500@gmail.com.

** Graduada em Direito pelo Centro Universitário AGES, UniAGES. Pós-graduanda Lato Sensu em Direito de Processo Civil e em Advocacia no Direito Digital e Proteção de Dados. Email:gcarvalhoo06@gmail.com.

*** Graduada em Letras Vernácula pela UNEB. Graduada em Direito pelo Centro Universitário AGES, UniAGES. Pós-graduada em Docência do Ensino Superior pela Faculdade de Ciências e Tecnologias, FTC. Pós-graduanda Lato Sensu em Direito do Processo Civil pela Faculdade Futura. E-mail: janainacardosofasb@gmail.com.
} 
which social distance is the WHO's primary guideline, the silence of these women and the consequent removal of friends and close relatives effectively becomes the biggest accomplice in gender violence.

Keywords: Pandemic. Structural Machismo. Domestic violence. Human rights.

Recebido em: 01/10/2020.

Aceito em: 27/10/2020. 


\section{INTRODUÇÃO}

A violência doméstica é um problema enfrentado no Brasil por muito tempo. E mesmo diante dos constantes casos de feminicídio e agressões e de outra banda, um maior enrijecimento da legislação com novas leis que criminalizam de forma diferente as agressões às mulheres e que tentam protegê-las, seja através da concessão de medidas protetivas ou de prisão do agressor ainda é um dos problemas que tem ganhado maiores proporções em períodos de pandemia.

Ocorre que, com o advento da COVID-19, período pelo qual nem sempre se tem como afastar a vítima do agressor e ainda inviabiliza as denúncias diante da necessidade do distanciamento social fica nítido que essa violência sempre existiu, mas não era tão evidente quando comparado a essa orientação dos casais permanecerem em suas casas por mais tempo.

A problemática utilizada em torno deste trabalho funciona como base para o entendimento dos impactos da pandemia na vida das pessoas que sofrem a violência doméstica no que se refere a sopesar normas jurídicas para entender as consequências de ordem psíquica e da dignidade humana, sendo a responsabilidade de proteção do Estado o objeto a ser analisado atentando em torno dos direitos e princípios.

Assim, foi utilizada como metodologia a exploratória, vez que o erguimento bibliográfico foi o arcabouço teórico com pesquisas em legislações, sites oficiais de levantamento de dados e decisões judiciais que possibilitaram a estrutura dialética no qual mensurou a prática com a teoria e contribuiu com o referenciamento.

É sabido que há uma interface entre machismo estrutural e violência de gênero e que essa situação é fortalecida no cotidiano brasileiro marcado pela cultura do patriarcado, que advém da religião, piadas, e até uma suposta natureza biológica de superioridade masculina, sendo pois a hipótese inicial para explicar o aumento exponencial dos casos de violência domestica.

A questão ganha maior proporção quando movimentos por luta de igualdade de direitos têm efervescência em nível mundial a partir da luta antirracista e de casos emblemáticos como Floyde e Miguel - situações que aguçaram a necessidade da luta contra todas as formas de violência estrutural e a luta por igualdade de direitos para 
as mulheres amolda-se perfeitamente a essa situação.

As razões que construíram a violência doméstica enquanto pilar do poder patriarcal e que corroboram para a consequente desigualdade entre homens e mulheres precisam ser combatidas por toda a sociedade não apenas por mulheres. Todavia, como bem salientou a filósofa Djamila Ribeiro em sua obra "Lugar de Fala" os temas relacionados a racismo, opressão de gênero ainda é visto como algo chato, "mimimi" ou outras formas de deslegitimação. E assim, o debate necessário em busca da tomada de consciência é naturalmente visto de forma agressiva ou inapropriada, pois confronta o poder. (RIBEIRO, 2017).

O machismo estrutural que é a forma como posicionamos os ideais de ser mulher e ser homem dentro de uma sociedade, definindo e dividindo papéis em razão do gênero e dando um tratamento desigual para as pessoas. É uma supressão social da ideia de igualdade entre homens e mulheres que acontece por tanto tempo que se passa de geração em geração e as mulheres têm seus espaços nas posições sociais inferiorizados em razão destas distinções, tendo que lutar por um espaço que naturalmente e legislativamente é seu de direito.

Ainda que existam direitos fundamentais trazidos pela Constituição da República Federativa do Brasil de 1988, que são os pilares da legislação, a forte predominância da cultura do machismo e dominação masculina é forte na sociedade e suprime o ideal de igualdade que vigora com força e incisão apenas no texto da Constituição da República Federativa do Brasil de 1988, tendo em vista que mulheres estão em condição de desigualdade, supressão de direitos e vulnerabilidade no que concerne a violência doméstica em todos os âmbitos de relação familiar com o gênero oposto.

Mesmo com todo avanço no arcabouço legislativo no sentido da proteção aos direitos das mulheres, proteção aos seus corpos e suas vidas, como a Lei 11.340/2006 (BRASIL, 2006) conhecida como Lei Maria da Penha, o que a sociedade manifesta não é a diminuição aos casos de violência, assim sabe-se que a endurecida na legislação como a previsão do feminicídio no Código Penal de 1940, trazido pela Lei 13.104/2015 (BRASIL, 2015) não modifica e não melhora a situação da mulher vítima de violência, muito pelo contrário, os casos vêm crescendo a todo instante, principalmente no contexto atual de pandemia. 
O aumento dessa violência é alarmante, pois vivencia-se tempos de tensão, seja pela crescente perda de empregos, de vidas, diminuição de salários e recursos, e principalmente pela maior convivência do violador com a vítima de violência doméstica. Assim, o crescimento dos números conduz a uma preocupação ainda maior, pois sabe-se que há muitas mulheres sem recursos e condições para denunciar, fato que tem agravado a situação.

Em dias hodiernos, em que a realidade mundial foi fortemente abalada em razão da pandemia às próprias estruturas familiares estão sendo modificadas, principalmente com a presença dos entes muito mais tempo nas respectivas residências e com grande parte do mundo sob quarentena, há uma preocupação crescente de que crianças e adultos que vivem em ambientes com abusadores em situação de vulnerabilidade econômica consigam fazer denúncias de violência convivendo em tempo integral com os abusadores.

Diante dessa problemática, o objetivo principal ancora-se em compreender o machismo enquanto prática estrutural e sua estreita relação com o aumento dos casos de violência de gênero em tempos de COVID-19. Logo, as reflexões que serão trazidas perpassam no seio dos movimentos sociais enquanto forma de ferramenta política, bem como na legislação em torno do combate a violência de gênero.

Por fim, vale mencionar que as hipóteses de resultados esperados permeiam na ideia de aguçar a reflexão dos leitores sobre a necessidade de abordar, debater e lutar contra o machismo estrutural e suas consequências que recaem na seara da violência doméstica e do próprio feminicídio.

\section{A VIOLÊNCIA DOMÉSTICA ENQUANTO PROBLEMA SOCIAL}

\subsection{O machismo estrutural como fonte do poder patriarcal}

A sociedade brasileira foi formada predominantemente por uma estrutura patriarcal, ou seja, pela dominância dos homens - aqui se entende como o gênero masculino - nas principais atividades econômicas e sociais que ensejaram o predomínio por eles deste espaço. A mulher teve seu espaço restrito as áreas domésticas e por muito tempo foi vista como propriedade do seu marido, tendo as 
leis civis acentuado e legitimado essa situação com imposições e restrições no que se refere ao nome, evidenciando a estrutura patriarcal, como bem aduz Dias ([2010?]):

O Código Civil de $1916^{[1]}$ obrigava a mulher a usar o nome do marido. A imposição da mudança de um dos atributos da personalidade tinha por justificativa a necessidade de identificação do núcleo familiar que surgia a partir do casamento. A feição marcadamente patriarcal da sociedade da época impunha que a sinalização da nova família ocorresse por meio do patronímico do varão. (DIAS, [2010?]).

O lugar da mulher era determinado por seu conjugue que detinha poder sobre seus bens, sobre sua vida profissional e sobre todo o ambiente familiar, o que só serviu para acentuar o lugar subalterno na relação familiar e na sociedade como um todo, que era destinado pra a mulher, como trazido por Dias ([2010?]):

Ao marido competia a representação legal da família, a administração dos bens comuns e dos bens próprios da esposa. Era ele o chefe da sociedade conjugal, tendo o direito de fixar o domicílio conjugal. Também lhe competia autorizar a profissão da mulher e a fixação da sua residência fora do teto conjugal $^{[2]}$. (DIAS, [2010?]).

As construções da sociedade e as determinações de lugar dos indivíduos nesta vem sendo mudado e remodelado com o passar dos anos, mas acontece que o Patriarcado ainda resulta grande influência dentro das relações existentes no âmbito da sociedade brasileira uma vez que tem relação com seus principais problemas, deste modo as divergências e subjugações sofridas pelas mulheres dentro do meio social, advém das mazelas trazidas pela predominância do poder patriarcal que para Scott (1995):

O patriarcado é uma forma de organização social onde suas relações são regidas por dois princípios basilares: as mulheres são hierarquicamente subordinadas aos homens, e os jovens estão subordinados hierarquicamente aos homens mais velhos, patriarcas da comunidade. (SCOTT, 1995, p. 77).

O machismo estrutural é uma das mazelas trazidas por essa ideia do poder patriarcal e consiste na ideia de como se posicionam os ideais de ser mulher e ser homem dentro de uma sociedade e as distinções dos papéis destes dentro da dinâmica social, acentuando assim a ideia da supremacia masculina, é como

\footnotetext{
${ }^{1}$ Art. 240 do CC de 16: A mulher assume, pelo casamento, com os apelidos do marido, a condição de sua companheira, consorte e auxiliar nos encargos da família.

${ }^{2}$ Art. 233 do Código Civil de 1916.
} 
Beauvoiur (1967) descreve, as pessoas torna-se o que são de acordo com as imposições sociais:

NINGUÉM nasce mulher: torna-se mulher. Nenhum destino biológico, psíquico, econômico define a forma que a fêmea humana assume no seio da sociedade; é o conjunto da civilização que elabora esse produto intermediário entre o macho e o castrado que qualificam de feminino. Somente a mediação de outrem pode constituir um indivíduo como um Outro. (BEAUVOIR, 1967, p. 9, grifo nosso).

Nesse contexto a própria conjuntura da palavra gênero e a necessidade de diferenciar homem de mulher serve para o mesmo efeito que na realidade é de salientar as desigualdades, sobretudo quando se visualiza a real situação das mulheres no contexto social de trabalho, familiar, educacional e na perspectiva até da violência doméstica, assim gênero segundo a concepção tratada por Melo (2003) tem o condão de:

[...] demonstrar e sistematizar as desigualdades socioculturais existentes entre mulheres e homens, que repercutem na esfera da vida pública e privada de ambos os sexos, impondo a eles papéis sociais diferenciados que foram construídos historicamente, e criaram polos de dominação e submissão. Impõe-se o poder masculino em detrimento dos direitos das mulheres, subordinando-as às necessidades pessoais e políticas dos homens, tornando-as dependentes. (MELO, 2003, p. 16).

Portanto, não a toa que distinções em tratamentos, nomenclaturas e papeis sociais são feitos, o condão não é meramente biológico, mas sim uma forma de imposição e segregação de espaço na sociedade, no qual mulheres tem o direito constitucional de igualdade tolhido em razão do machismo estrutural enraizado na sociedade patriarcal.

\subsection{Violência doméstica e o perfil das mulheres vítimas}

A violência doméstica é reflexo da sociedade brasileira e do machismo que prepondera nas relações familiares e sociais, esta advém do sentimento de posse que se tem sobre o corpo e a mulher, o que por muito tempo foi legitimado pela Lei $n^{\circ} 3.071$, de $1^{\circ}$ de janeiro de 1916 (BRASIL, 1916), mas que se refletiu por todo Estado, tendo em vista a falta de proteção e demais leis como o Estatuto da Mulher Casada que não conferia igualdade em relação ao homem, Saffioti (2004) discorre como as relações patriarcais influem no Estado "do mesmo modo como a as relações 
patriarcais, suas hierarquias, sua estrutura de poder contaminam toda a sociedade, 0 direito patriarcal perpassa não apenas a sociedade civil, mas impregna também o Estado." (SAFFIOTI, 2004, p. 54).

A mulher era vista como propriedade do seu pai até o casamento e após este era de propriedade do seu esposo e não era comum e tão pouco aceitável que se entrasse nos ambientes domésticos para proteção da mulher, mesmo nos casos de violência física, pois desde muito tempo se ouve a famosa expressão que "em brigada de marido e mulher ninguém mete a colher", em razão de tal conjuntura por muito tempo a violência doméstica foi vista, vivida e normalizada pela coletividade, em razão dos ideais do patriarcado e da mulher como sujeito submisso na relação familiar.

Contudo, com o advento de movimentos como o feminismo, no qual as mulheres passaram a lutar pelo princípio constitucional da igualdade, as coisas começaram a mudar e a opressão familiar e violência doméstica deixou de ser restrita ao interesse familiar e passou a ter o condão do interesse social, os direitos das mulheres começaram a ganhar força e visibilidade, como discorre Dias e Souza (2010):

\begin{abstract}
Mas desta vez, não apenas estatísticas quase anônimas, mesmo que incontestáveis, ou simples vontade de alguns observadores lúcidos da situação da mulher oprimida em sua própria casa, mas a perseverança, o sofrimento e a capacidade tenaz em reverter um infortúnio pessoal conquistaram o recurso para, com este instrumento legal, abalar a violência, nas várias faces com que flagela não apenas a mulher, mas a família e a sociedade. A vítima que se insurge de fato, também o faz em favor do social, contaminado tantas vezes pelo silêncio e pela omissão relativos aos conflitos familiares desta natureza. Se os movimentos feministas do séc. XX vinham concluindo que nenhuma questão social é alheia ao feminismo, a recíproca então é verdadeira. Nenhuma das questões dos direitos da mulher se afasta do interesse social. (DIAS; SOUZA, 2010).
\end{abstract}

Assim, sabe-se que violência de gênero de acordo com a Coordenadoria Estadual da Mulher em Situação de Violência Domestica do Tribunal de Justiça do Rio Grande do Sul ([20--?]) é "violência sofrida pelo fato de se ser mulher, sem distinção de raça, classe social, religião, idade ou qualquer outra condição, produto de um sistema social que subordina o sexo feminino", ocorre que ainda há um tipo de violência sofrido pelas mulheres também que é ainda mais comum, a violência doméstica que segundo a Coordenadoria Estadual da Mulher em Situação de 
Violência Domestica do Tribunal de Justiça do Rio Grande do Sul ([20--?]) ocorre "quando ocorre em casa, no ambiente doméstico, ou em uma relação de familiaridade, afetividade ou coabitação", está não se restringe apenas a determinada classe social, vai muito além.

Por essa razão, determinar um perfil da vítima de violência doméstica é bem difícil, uma vez que muito embora pareça estar atrelada as classes mais pobres da sociedade, é um verdadeiro mito falar que ela só aconteça nesse contexto, como bem trouxe o Instituto Maria da Penha (c2018):

A violência doméstica é um fenômeno que não distingue classe social, raça, etnia, religião, orientação sexual, idade e grau de escolaridade. Todos os dias, somos impactados por notícias de mulheres que foram assassinadas por seus companheiros ou ex-parceiros. Na maioria desses casos, elas já vinham sofrendo diversos tipos de violência há algum tempo, mas a situação só chega ao conhecimento de outras pessoas quando as agressões crescem a ponto de culminar no feminicídio. (INSTITUTO MARIA DA PENHA, c2018).

Assim, visualiza-se que é uma questão extremamente ligado ao formato social e a ideia de supremacia masculina e do patriarcado, do que somente construções pautadas em classe e cor, pois em todo o bojo da sociedade a violência doméstica perpetua e agora, em tempos da Pandemia do COVID-19, acentua-se pelo fato do isolamento social e da proximidade entre a vítima e o agressor.

\section{OS DIREITOS FUNDAMENTAIS NA PROTEÇÃO DA MULHER}

\subsection{0 princípio da igualdade}

A Constituição da República Federativa do Brasil de 1988 (BRASIL, 1988) tem como princípio fundamental e basilar a Igualdade, sendo esta tratada como objetivo fundamental da nação tendo em vista que o artigo $3^{\circ}$ da Constituição da República Federativa do Brasil de 1988 dispõe a esse respeito:

Art. 30 Constituem objetivos fundamentais da República Federativa do Brasil:

[...] IV - promover o bem de todos, sem preconceitos de origem, raça, sexo, cor, idade e quaisquer outras formas de discriminação. [...]. (BRASIL, 1988).

Por essa razão, a não discriminação em razão do sexo é protegida pelo texto constitucional e é também um dos objetivos fundamentais da nação, buscando assim 
a proteção e inclusão da igualdade no ordenamento jurídico, uma vez que o texto constitucional é base para as legislações infraconstitucionais e do mesmo modo disciplina a sociedade.

O Princípio da Igualdade é fundamental para a sociedade, assim vir expresso na Constituição da República Federativa do Brasil de 1988 (BRASIL, 1988) só afirma o quanto é importante que se frise, pois ainda que pareça óbvio que todas as pessoas são iguais, sobretudo no que concerne a lei, a realidade é bem diferente, sobretudo quando se olha para a situação da mulher tanto no mercado de trabalho, quanto nas relações familiares, domésticas e principalmente nas conjugais.

O texto constitucional é claro ao afirmar que todos somos iguais perante a lei e homens e mulheres possuem as mesmas obrigações no seu artigo $5^{\circ}$ :

Art. $5^{0}$ Todos são iguais perante a lei, sem distinção de qualquer natureza, garantindo-se aos brasileiros e aos estrangeiros residentes no País a inviolabilidade do direito à vida, à liberdade, à igualdade, à segurança e à propriedade, nos termos seguintes: I - homens e mulheres são iguais em direitos e obrigações, nos termos desta Constituição; [...]. (BRASIL, 1988).

Porém no que concerne aos direitos ainda vem sendo necessário que haja muitas lutas para que esse direito fundamental de igualdade de fato se efetive, pois a mulher vem sendo discriminada no mercado de trabalho com salários mais baixos, muito embora a proteção ao mercado de trabalho da mulher seja garantida no artigo 70, inciso XX da Constituição da República Federativa do Brasil de 1988 (BRASIL, 1988), há desigualdades no ambiente familiar com maiores e principais obrigações no que tange a organização da família e cuidados com os filhos, e ainda é subjugada em muitos casos na relação conjugal, uma vez que em algumas situações é tratada como propriedade do marido que se acha no direito de agredi-la.

A Constituição da República Federativa do Brasil de 1988 ainda traz no seu texto a proteção da família por parte do Estado e garante que os direitos e deveres da sociedade conjugal de dará de forma igualitária para homens e mulheres, assim o artigo 226 versa sobre essa proteção quando dispõe que "Art. 226. A família, base da sociedade, tem especial proteção do Estado. [...] $\S 5^{\circ}$ Os direitos e deveres referentes à sociedade conjugal são exercidos igualmente pelo homem e pela mulher. [...]". (BRASIL, 1988). 
Portanto, muito embora existam princípios e direitos fundamentais que colocam a mulher em posição de igualdade, na prática ainda não se enxerga tanta efetividade, uma vez que é necessário que se encrudesça a legislação com para que o já mencionado e diplomado na Constituição da República Federativa do Brasil de 1988 passe a vigorar ou para coibir o latente desrespeito.

\section{ENCRUDESCIMENTO NA LEGISLAÇÃO PARA A PROTEÇÃO DE MULHERES VÍTIMAS DE VIOLÊNCIA}

\subsection{Lei Maria da Penha - Lei 11.340/06}

A Lei 11.340/2006 (BRASIL, 2006) mais conhecida como Lei Maria da Penha, adentrou o ordenamento jurídico brasileiro com o ímpeto de criminalizar a situação da violência doméstica, uma vez que apenas os resultados desta violências quando se enquadravam-se em crimes já tipificados, como a lesão corporal por exemplo, é que poderiam ser abarcados e protegidos pela esfera penal.

Os movimentos feministas, as comoções sociais e a busca de mulher por espaço, igualdade e proteção dentro da sociedade culminaram em avanços doutrinários e legislativos, até que a Lei Maria da Penha fosse criada, muito embora o estopim para essa proteção tenha sido a sanção internacional no caso de Maria da Penha Maia, caso este que mostra o quanto os princípios constitucionais na proteção da mulher são inaplicados, Maria Berenice Dias e Ivone M. C. Coelho de Souza (2010), narra a cruel história vivida por Maria da Penha o qual nomeou a Lei e pela qual o Brasil deveria envergonhar-se:

\footnotetext{
A bioquímica cearense Maria da Penha Maia foi vítima de várias e cruéis tentativas de homicídio no interior da residência marital, em 1983, sendo que em uma foi atingida por disparos de arma de fogo, tornou-se paraplégica, condição em que vive até hoje. $O$ autor dos ataques, seu marido e colega foi detido e liberado várias vezes (encontra-se hoje em liberdade, após pena de 2 anos de detenção), enquanto persistia na intenção criminosa, até que organizações internacionais pressionassem as autoridades brasileiras a implantar finalmente justiça. Todo este arrastado capítulo de uma verdadeira crônica de morte anunciada redundou na luta de 20 anos pela qual finalmente a lei pode ser promulgada. (DIAS; SOUZA, 2010).
}

Muito embora a Lei Maria da Penha não extinguiu e solucionou de vez a situação da violência doméstica, ela é de grande importância tanto para o 
ordenamento jurídico, quanto para a sociedade, uma vez que expressa uma vitória das mulheres na busca pela promoção de igualdade que Ihes é conferida pela Constituição da República Federativa do Brasil de 1988, pois ela pune o agressor de forma mais severa e traz mecanismos para proteger a mulher vítima de violência familiar. (BRASIL, 1988).

A violência doméstica é uma questão intimamente ligada a sociedade, principalmente em razão da cultura machista e opressora no qual o Brasil se solidificou, por esse motivo é que a Lei Maria a Penha sofreu e sofre muitas críticas que tentam diminuir a sua verdadeira importância e efetividade com bem traz Dias (2006):

\begin{abstract}
Ainda assim, por mais que se tente minimizar sua eficácia e questionar sua valia, Maria da Penha veio para ficar. É um passo significativo para assegurar à mulher o direito à sua integridade física, psíquica, sexual e moral. Aliás, as vitórias femininas sempre foram marcadas por muitas lutas. Desde o direito ao voto até o direito à liberdade sexual, árduo tem sido o caminho para a conquista da igualdade. (DIAS, 2006).
\end{abstract}

A Lei 11.340/2006 avançou e foi conquista de uma luta árdua dentro de uma sociedade marcada pelo patriarcado, pela ideia de que as relações conjugais não devem ser disciplinadas ou interferidas por terceiros. Ocorre que ainda não foi o bastante para coibir totalmente a violência dentro do âmbito familiar e social, desta forma após nove anos de sua criação, em 09/03/2015 foi promulgada a Lei 13.104 que inseriu no Código Penal de 1940 mais uma modalidade de homicídio qualificado, qual seja o feminicídio. (BRASIL, 2006, 2015).

\title{
4.2 Lei do Feminicídio - Lei 13.104/2015
}

A Lei 13.104/2015 (BRASIL, 2015) também conhecida como lei do feminicídio, incorpora mais uma qualificadora ao crime de homicídio, crime descrito no artigo 121 do Código Penal de 1940, quando este for cometido contra uma mulher e motivado em razão da condição de mulher e também modifica a lei de crimes hediondos, incluindo o feminicídio no rol:

Art. $1^{0} \mathrm{O}$ art. 121 do Decreto-Lei no 2.848, de 7 de dezembro de 1940 Código Penal , passa a vigorar com a seguinte redação:

"Homicídio simples

Art. 121. 


\section{Homicídio qualificado}

$\S 20$

\section{Feminicídio}

VI - contra a mulher por razões da condição de sexo feminino:

§ $2^{\circ}$-A Considera-se que há razões de condição de sexo feminino quando o crime envolve:

I - violência doméstica e familiar;

II - menosprezo ou discriminação à condição de mulher.

\section{Aumento de pena}

$\S 70$ A pena do feminicídio é aumentada de $1 / 3$ (um terço) até a metade se o crime for praticado:

I - durante a gestação ou nos 3 (três) meses posteriores ao parto;

II - contra pessoa menor de 14 (catorze) anos, maior de 60 (sessenta) anos ou com deficiência;

III - na presença de descendente ou de ascendente da vítima." (NR)

Art. $2^{\circ} \mathrm{O}$ art. $1^{\circ}$ da Lei $n^{\circ} 8.072$, de 25 de julho de 1990, passa a vigorar com a seguinte alteração:

"Art. 10

I - homicídio (art. 121), quando praticado em atividade típica de grupo de extermínio, ainda que cometido por um só agente, e homicídio qualificado (art. 121, § 20, I, II, III, IV, V e VI);

(BRASIL, 2015).

(NR) $\quad[\ldots]$.

Ocorre que mesmo com uma lei mais dura e considerada como crime hediondo que muda muita coisa no processo penal, sistema de regime e progressão do mesmo, não foi o suficiente para que houvessem diminuições dos números dos casos em que mulheres estão sendo vítimas de homicídios pela sua condição de gênero, a Câmara Legislativa em 09/03/2020 publicou no seu site uma matéria que aponta o crescimento dos casos mesmo após a Lei:

\footnotetext{
Mas, apesar da legislação, o número de feminicídios tem seguido o caminho contrário de homicídios dolosos e roubos seguidos de morte, que diminuíram no ano passado: um levantamento feito pelo jornal Folha de S. Paulo mostrou que, em 2019, houve 1.310 assassinatos decorrentes de violência doméstica ou motivados pela condição de gênero, características do feminicídio. Foi uma alta de 7,2 \% em relação a 2018. Coordenadora da bancada feminina na Câmara, a deputada Professora Dorinha Seabra Rezende (DEM-TO) acredita que a Lei do Feminicídio foi um avanço no combate à violência contra as mulheres, mas ainda é preciso fazer mais. "Há mais de 240 projetos ligados a esse tema da violência contra a mulher, em especial a tipificação do feminicídio", informou. (BITTAR, 2020).
}

Assim o que se pode perceber após cinco anos da Lei de feminicídio vigorar e produzir efeitos no ordenamento jurídico brasileiro é que a simples imposição legal e o recrudescimento das leis penais não garantem a efetividade dessas leis sobre o 
ponto de vista do caráter coibidor e educacional da sociedade, visto que os problemas de cunho familiar, afetivo e a forma como a mulher é vista e tratada em todos os espaços da sociedade é que de fato devem ser alcançados e por outros meios que não a mera imposição legislativa, já que se trata de questões culturais e sociais.

\section{O AUMENTO DA VIOLÊNCIA NA PANDEMIA}

\subsection{Violência doméstica: tão letal quanto o coronavírus}

A COVID 19 e consequentemente as orientações da OMS (Organização Mundial de Saúde) trouxeram uma nova dinâmica de convivência familiar. Sendo que alguns entes ficavam muito mais tempo fora de casa em seus respectivos ambientes de trabalho, por perderem seus empregos formais ou até mesmo para adaptação na modalidade remota passaram a ter uma convivência mais efetiva nos lares.

Com essa reestruturação do permanecer mais tempo em casa a violência doméstica e sua série de abusos ganhou intensidade no país, que conforme dito nos títulos alhures possui fortes heranças patriarcais.

Frisa-se que essa violência doméstica conforme preceitua a Lei no 11.340 (BRASIL, 2006) contempla várias manifestações de abusos físicos, psicológicos e patrimoniais como se depreende do artigo abaixo:

Art. 70 São formas de violência doméstica e familiar contra a mulher, entre outras:

I - a violência física, entendida como qualquer conduta que ofenda sua integridade ou saúde corporal;

II - a violência psicológica, entendida como qualquer conduta que lhe cause dano emocional e diminuição da autoestima ou que the prejudique e perturbe o pleno desenvolvimento ou que vise degradar ou controlar suas ações, comportamentos, crenças e decisões, mediante ameaça, constrangimento, humilhação, manipulação, isolamento, vigilância constante, perseguição contumaz, insulto, chantagem, ridicularização, exploração e limitação do direito de ir e vir ou qualquer outro meio que the cause prejuízo à saúde psicológica e à autodeterminação;

II - a violência psicológica, entendida como qualquer conduta que lhe cause dano emocional e diminuição da autoestima ou que the prejudique e perturbe o pleno desenvolvimento ou que vise degradar ou controlar suas ações, comportamentos, crenças e decisões, mediante ameaça, constrangimento, humilhação, manipulação, isolamento, vigilância constante, perseguição contumaz, insulto, chantagem, violação de sua intimidade, ridicularização, exploração e limitação do direito de ir e vir ou 
qualquer outro meio que lhe cause prejuízo à saúde psicológica e à autodeterminação; (Redação dada pela Lei no 13.772, de 2018).

III - a violência sexual, entendida como qualquer conduta que a constranja a presenciar, a manter ou a participar de relação sexual não desejada, mediante intimidação, ameaça, coação ou uso da força; que a induza a comercializar ou a utilizar, de qualquer modo, a sua sexualidade, que a impeça de usar qualquer método contraceptivo ou que a force ao matrimônio, à gravidez, ao aborto ou à prostituição, mediante coação, chantagem, suborno ou manipulação; ou que limite ou anule o exercício de seus direitos sexuais e reprodutivos;

IV - a violência patrimonial, entendida como qualquer conduta que configure retenção, subtração, destruição parcial ou total de seus objetos, instrumentos de trabalho, documentos pessoais, bens, valores e direitos ou recursos econômicos, incluindo os destinados a satisfazer suas necessidades;

$\mathrm{V}$ - a violência moral, entendida como qualquer conduta que configure calúnia, difamação ou injúria. (BRASIL, 2006).

Esse artigo deixa claro que nesse tipo de violência todas as manifestações de abusos advêm da representação de poder oriunda de um dos membros da família. Insta mencionar que essa violência advém de relações íntimas de afeto com a vítima. É fato que com as orientações da Organização Mundial de Saúde, muitas mulheres passaram a conviver muito mais com a abusividade de seus companheiros e consequentemente os casos de violência corroboraram para o aumento das agressões.

Há uma nítida relação entre o aumento dessas agressões e as marcas da crise. E infelizmente o desemprego e todos os demais impactos causados na economia causou na maioria dos homens agressores essa sensação de estresse e de vingar-se dos problemas em suas companheiras. Para Débora Veneral (2020):

A pandemia não é a causa da violência, mas, sem dúvidas, tem contribuído para seu agravamento. O cenário criado dentro dos lares em razão do isolamento social propicia a eclosão de conflitos e acentua os embates já existentes. De um lado, para as mulheres/vítimas, além do aumento do trabalho doméstico, há o cuidado com crianças, idosos e familiares. $E$, não bastasse isso, muitas ainda dependem financeiramente de seu parceiro. De outro, para os homens/agressores, o nível de estresse eleva-se em decorrência do medo de adoecer, da insegurança quanto ao futuro, da impossibilidade de convívio social ou, ainda, da iminência de redução de renda ou de desemprego. (VENERAL, 2020).

Como bem pontuou a advogada no excerto acima, a violência ora discutida precede a COVID 19, mas essa situação literalmente intensificou a prática dessas violências nos lares brasileiros, que tem como público alvo as mulheres. Todavia, a 
Lei no 11.340 (BRASIL, 2006) traz em seu escopo algumas limitações que na visão do jurista Renato Brasileiro de Lima (2016):

\begin{abstract}
"O objetivo da Lei Maria da Penha não foi o de conferir uma proteção indiscriminada a toda e qualquer mulher, mas apenas àquelas que efetivamente se encontrarem em uma situação de vulnerabilidade. É indispensável, portanto, que a vítima esteja em uma situação de hipossuficiência física ou econômica, enfim, que a infração tenha como motivação a opressão à mulher. Ausente esta violência de gênero, não se aplica a Lei Maria da Penha." (LIMA, 2016 apud MOREIRA, 2019).
\end{abstract}

Nas linhas descritas acima, é visível que essa situação de vulnerabilidade em tempos de Pandemia ganha efetivamente maiores proporções, ao considerar-se que a violência física é mais fácil de ser identificada há uma certa dificuldade em perceber a violência psicológica, que traz um controle excessivo e uma vigilância que ultrapassa os limites do bom senso.

Vale ressaltar que a referida lei deve ser considerada um grande avanço para a legislação brasileira, principalmente por trazer a tona a necessidade uma igualdade nos casos concretos entre homem e mulher. Há em meio a essa crise uma necessidade latente de maior e correta aplicação dessa Lei para que se consiga garantir o mínimo de proteção as mulheres vítimas de violência, que são naturalmente e estruturalmente silenciadas.

\title{
6 CONCLUSÃO
}

Ante o exposto, e a efetiva relação entre as fontes teóricas e pesquisa exploratória ora utilizada foi possível perceber que esse trabalho teve como principal objetivo analisar o impacto da Pandemia em razão da COVID-19 nas relações familiares e diretamente na violência doméstica, de maneira a ponderar a situação da mulher como indivíduo amparado pela Constituição da República Federativa do Brasil de 1988 com relação ao Princípio da Igualdade, e a forma como esta vem sendo tratada dentro da sociedade.

Deste modo, foram feitas críticas à forma como a mulher vem lutando pela condição de igualdade mesmo este sendo um direito constitucionalmente garantido, e como os abusos e violência permeiam a vida delas em vários cenários de suas vidas em razão da cultura machista e dos reflexos do patriarcado. 
Não adianta endurecer as leis para como forma de coibir a violência doméstica e a violência contra a mulher, o que de fato necessita-se é de práticas educacionais para desmistificar o machismo estrutural e a ideia de mulheres enquanto propriedade de seus companheiros. Para que essa desmistificação aconteça é primordial que as bandeiras feministas sejam hasteadas por toda a sociedade e não somente por mulheres.

Conforme o exposto ao longo desse artigo é visível que a opressão de gênero possui estruturas históricas que se reverberam e reiteram a desigualdade. Daí decorre a necessidade de uma educação feminista enquanto concepção de vida e de valorização do respeito.

Pois, conforme foi debatido a violência doméstica foi tão fortemente construída que a ideia é que ela seja vista de maneira "normal" e esse processo de naturalização faz com que muitas mulheres nem se deem conta que são vítimas, pois culturalmente foram ensinadas a confundir submissão com proteção e principalmente incentivadas ao silêncio desde cedo.

Dessa feita, ao compreender que a violência contra a mulher é uma construção social fruto de uma representação de poder que prega a desigualdade de forças entre homens e mulheres é crucial que essa seja combatida diariamente e contemple os processos educacionais e culturais do país. Pois só assim, as mulheres serão efetivamente tratadas sob o viés da igualdade.

\section{REFERÊNCIAS}

BEAUVOIR, S. O segundo sexo: a experiência vivida. Tradução: Sergio Milliet. 2. ed. São Paulo: Difusão Europeia do Livro, 1967. v. 2.

BITTAR, P. Lei do feminicídio faz cinco anos: deputadas destacam a necessidade de votar outras propostas que aprimorem o combate às violência contra a mulher.

Câmara dos Deputados, Brasília, DF, 2020. Disponível em: https://www.camara.leg.br/noticias/643729-lei-do-feminicidio-faz-cinco-anos/. Acesso em: 19 out. 2020.

BRASIL. [Constituição (1988)]. Constituição da República Federativa do Brasil de 1988. Brasília, DF: Presidência da República, 1988. Disponível em: http://www.planalto.gov.br/ccivil_03/constituicao/constituicao.htm. Acesso em: 30 set. 2020. 
BRASIL. Lei $\mathbf{n} .{ }^{0}$ 11.340, de 7 de agosto de 2006. Cria mecanismos para coibir a violência doméstica e familiar contra a mulher, nos termos do $\S 8^{\circ}$ do art. 226 da Constituição Federal, da Convenção sobre a Eliminação de Todas as Formas de Discriminação contra as Mulheres e da Convenção Interamericana para Prevenir, Punir e Erradicar a Violência contra a Mulher; dispõe sobre a criação dos Juizados de Violência Doméstica e Familiar contra a Mulher; altera o Código de Processo Penal, o Código Penal e a Lei de Execução Penal; e dá outras providências. Brasília, DF: Presidência da República, 2006. Disponível em: http://www.planalto.gov.br/ccivil_03/_ato2004-2006/2006/lei/l11340.htm. Acesso em: 30 set. 2020.

BRASIL. Lei n. ${ }^{\mathbf{0}}$ 13.104, de 9 de março de 2015. Altera o art. 121 do Decreto-Lei no 2.848, de 7 de dezembro de 1940 - Código Penal, para prever o feminicídio como circunstância qualificadora do crime de homicídio, e 0 art. $1^{\circ}$ da Lei no 8.072 , de 25 de julho de 1990, para incluir o feminicídio no rol dos crimes hediondos. Brasília, DF: Presidência da República, 2015. Disponível em:

http://www.planalto.gov.br/ccivil_03/_ato2015-2018/2015/lei/l13104.htm. Acesso em: 30 set. 2020.

BRASIL. Lei n. ${ }^{0}$ 3.071, de $1^{\circ}$ de janeiro de 1916. Código Civil dos Estados Unidos do Brasil. Rio de Janeiro: Presidência da República, 1916. Disponível em: http://www.planalto.gov.br/ccivil_03/leis//3071.htm. Acesso em: 19 out. 2020.

COORDENADORIA ESTADUAL DA MULHER EM SITUAÇÃO DE VIOLENCIA DOMESTICA DO TRIBUNAL DE JUSTIÇA DO RIO GRANDE DO SUL. Tipos de Violência Doméstica e Familiar. Tribunal de Justiça do Rio Grande do Sul, [Rio Grande do Sul], [20--?]. Disponível em: https://www.tjrs.jus.br/novo/violenciadomestica/orientacoes/tipos-de-violencia-domestica-e-familiar/. Acesso em: 15 ago. 2020.

DIAS, M. B. A violência doméstica na Justiça. Instituto Brasileiro de Direito da Família, [S. I.], 2006. Disponível em: https://www.ibdfam.org.br/artigos/234/A+viol\%C3\%AAncia+dom\%C3\%A9stica+na +Justi\%C3\%A7a. Acesso em: 15 ago. 2020.

DIAS, M. B. Em nome do quê. Maria Berenice Dias, [S. I.], [2010?]. Disponível em: http://www.mariaberenice.com.br/manager/arq/(cod2_727)15_em_nome_do_que.p df. Acesso em: 19 out. 2020.

DIAS, M. B.; SOUZA, I. M. C. C. Lei Maria da Penha: sentimento e resistência à violência doméstica. Instituto Brasileiro de Direito da Família, [S. I.], 2010. Disponível em:

https://www.ibdfam.org.br/artigos/660/Lei+Maria+da+Penha\%3A+Sentimento+e+R esist\%C3\%AAncia+\%C3\%A0+Viol\%C3\%AAncia+Dom\%C3\%A9stica. Acesso em: 15 ago. 2020. 
INSTITUTO MARIA DA PENHA. Mitos da violência doméstica. Instituto Maria Da Penha, [S. I.], c2018. https://www.institutomariadapenha.org.br/violenciadomestica/o-que-e-violencia-domestica.html. Acesso em: 15 ago. 2020.

LIMA, Renato Brasileiro de. Legislação criminal especial comentada: volume único. 4. ed. rev., atual. e ampl. Salvador: JusPODIVM, 2016.

MELO, Mônica de. $\mathbf{O}$ que é violência contra a mulher. São Paulo: Brasiliense, 2003.

MOREIRA, I. Toda violência contra a mulher é disciplinada pela Lei Maria da Penha?. O Rio Branco, [S. I.], 2019. Disponível em:

https://www.oriobranco.net/colunista/27-08-2019-toda-violencia-contra-a-mulher-edisciplinada-pela-lei-maria-da-penha/27-08-2019-toda-violencia-contra-a-mulher-edisciplinada-pela-lei-maria-da-penha. Acesso em: 29 set. 2020.

RIBEIRO, D. 0 que é lugar de fala?. Belo Horizonte: Letramento, 2017.

SAFFIOTI, H. Violência de gênero: poder e impotência. São Paulo: Editora Fundação Revinter, 2004.

SCOTT, J. Gênero: uma categoria útil de análise histórica. Educação \& Realidade, [S. I.], v. 20, n. 2, p. 71-99, jul./dez. 1995. Disponível em:

https://seer.ufrgs.br/index.php/educacaoerealidade/article/view/71721. Acesso em: 15 ago. 2020.

VENERAL, D. Violência contra a mulher e Covid-19: a dupla pandemia. EcoDebate, [S. I.], 2020. Disponível em: https://www.ecodebate.com.br/2020/08/21/violenciacontra-a-mulher-e-covid-19-a-dupla-pandemia/. Acesso em: 15 ago. 2020. 